\title{
Role of IgG Chlamydia antibody in tubal factor infertility
}

\author{
Sheila Balakrishnan ${ }^{1}$, Anitha Malathi ${ }^{1 *}$, Geetha Raveendran², \\ Dolly Johnrose', Sreekumari Radha ${ }^{1}$
}

\begin{abstract}
${ }^{1}$ Department of Obstetrics and Gynecology, SAT Hospital, Government Medical College, Trivandrum, Kerala, India ${ }^{2}$ Department of Microbiology, Government Medical College, Trivandrum, Kerala, India
\end{abstract}

Received: 19 January 2017

Revised: 20 January 2017

Accepted: 28 January 2017

\author{
*Correspondence: \\ Dr. Anitha Malathi, \\ E-mail: dranitharajamohan@yahoo.com
}

Copyright: (C) the author(s), publisher and licensee Medip Academy. This is an open-access article distributed under the terms of the Creative Commons Attribution Non-Commercial License, which permits unrestricted non-commercial use, distribution, and reproduction in any medium, provided the original work is properly cited.

\begin{abstract}
Background: Chlamydial infection is considered to be one of the important causes of tubal factor infertility. This study will help to explore the relationship between positive Chlamydial infection and tubal damage in infertile women assessed by diagnostic laparoscopy. The results will help to determine whether a policy of routine screening for Chlamydia antibody is justifiable in infertile women to suspect tubal factor so that they can be taken up for laparoscopy earlier.

Methods: A prospective study was performed on 158 consecutive patients who underwent laparoscopy as part of infertility evaluation. About $5 \mathrm{~mL}$ of venous blood was drawn preoperatively to detect Chlamydia IgG antibody in all the patients by ELISA. The laparoscopic findings were documented and the relationship to Chlamydial antibody evaluated.

Results: Of the 158 patients who underwent laparoscopy, 95 patients had evidence of tubal disease as evidenced by unilateral or bilateral tubal block, peritubal adhesions, hydrosalpinx, beading of the tube and unhealthy shaggy appearance. Of the 95 patients with documented tubal disease at laparoscopy, 14 (14.7\%) had antibodies to Chlamydia. Of the 63 patients with normal tubes, $12(19 \%)$ had Chlamydial positivity. The difference is not statistically significant. However of the 26 patients who were positive for Chlamydia antibodies 14 patients (53.8\%) had abnormal tubes. Out of the 158 patients who underwent laparoscopy 26 patients were positive for Chlamydia. Hence the prevalence in our study is $16.4 \%$ (26/158). The sensitivity is $14.7 \%$ and the specificity is $81 \%$.

Conclusions: This study showed no difference in Chlamydial positivity between infertile women with abnormal tubes and those with normal looking tubes in our population. The absence of Chlamydial antibodies cannot be taken as a marker for normal tubes. Hence screening for chlamydial antibody can neither be used as a screening test for tubal factor infertility nor to decide on the need for laparoscopy in the present population.
\end{abstract}

Keywords: Chlamydia trachomatis, Chlamydia antibody test, Infertility, Laparoscopy

\section{INTRODUCTION}

This study aims to assess the role of Chlamydia IgG antibody in patients with tubal factor infertility among women with primary or secondary infertility attending a fertility clinic in a tertiary care hospital in Kerala, India. Tubal disease may be due to various etiologies including pelvic infections, endometriosis and previous pelvic surgery. Pelvic inflammatory disease (PID) can cause damage to the fallopian tubes leading to tubal obstruction or can be the cause of pelvic adhesions which prevent normal tubal movement, ovum pick-up and transport of the fertilized egg into the uterus. Tubal infertility has been estimated to follow in 12 percent, 23 percent, and 54 
percent of women following one, two, or three cases of PID, respectively. ${ }^{1}$ Nevertheless, a lack of PID history is not overly reassuring, as nearly one half of patients who are found to have tubal damage have no history of antecedent disease. ${ }^{2}$ Though data suggests that the etiology of PID is polymicrobial, Chlamydia trachomatis and Neisseria gonorrhoeae are the most common organisms associated with PID. Other microorganisms implicated in PID are Mycoplasma genitalium, Mycoplasma hominis, Ureaplasma spp, Veillonella spp. and other lower genital tract endogenous anaerobic and facultative bacteria, many of which are associated with bacterial vaginosis. ${ }^{3-5}$

Chlamydial infection is considered an important cause of pelvic inflammatory disease leading to consequent tubal damage and thereby infertility. There are a lot of studies regarding Chlamydial infection and infertility worldwide, but very few from the Indian subcontinent. We still do not know the extent of tubal infertility caused by Chlamydia in Indian women. The main challenge is that infection with Chlamydia is usually subclinical and asymptomatic and today with the syndromic approach policy it is very difficult to document Chlamydial infection.

This study will help to explore the relationship between positive Chlamydial infection and tubal damage in infertile women assessed by diagnostic laparoscopy. Laparoscopy is considered to be the gold standard for diagnosing tubal pathology. The results will help to determine whether a policy of routine screening of infertile women for Chlamydia $\operatorname{IgG}$ antibodies is justifiable and to comment on the role of this infection in tubal damage. Objective of the study was to evaluate the association of Chlamydia trachomatis $\operatorname{IgG}$ antibody (CAT) with tubal factor infertility.

\section{METHODS}

A prospective study was done in women undergoing laparoscopy at the Reproductive Medicine unit in SAT Hospital, Government Medical College Trivandrum, India for 1 year in 2015.158 consecutive women who underwent laparoscopy were included in the study. Women with obvious evidence of endometriosis on ultrasound were excluded from the study. Clearance was obtained from the Institutional Review Board and Ethics
Committee. Written informed consent was obtained from all the subjects.

A detailed history was taken from all the subjects and demographic details, type and duration of infertility and previous pregnancy loss recorded. The symptomatology was also noted. Infertility was defined as failure to conceive after one year of unprotected intercourse. Laparoscopy was performed for all patients with suspicion of tubal infertility like abnormal findings on hysterosalpingogram or ultrasound. Other indications were suspected endometriosis, myomectomy, laparoscopic ovarian drilling and unexplained infertility. Laparoscopy was performed in the proliferative phase by two surgeons and the pelvis was examined in detail with special reference to the appearance of the tubes.

Chromotubation was also done. Meticulous documentation of the laparoscopic findings was done. About $5 \mathrm{~mL}$ of venous blood was drawn preoperatively to detect Chlamydia IgG antibody in all the patients. The serum samples were stored in the deep freezer in the department of Microbiology, Government Medical College Trivandrum. Chlamydia IgG antibodies were detected using readymade ELISA kit (CT054GCalbiotech Inc). Antibody Index interpretation was as follows (<0.9-no detectable antibody; 0.9-1.1- borderline positive; $>1.1$ - detectable antibody).

Data was expressed in frequency distribution and data analysis was performed using SPSS Version 22.0. Between group comparisons of qualitative variables were analysed by Chi Square Test. A p value of 0.005 was taken as the level of significance.

\section{RESULTS}

Of the 158 patients who underwent laparoscopy, 95 patients had evidence of tubal disease as evidenced by unilateral or bilateral tubal block, peritubal adhesions, hydrosalpinx, beading of the tube and unhealthy shaggy appearance. Out of the 158 patients who underwent laparoscopy 26 patients were positive for Chlamydia antibody. Hence the prevalence in our study is $16.4 \%$ $(26 / 158)$. Of the 95 patients with documented tubal disease at laparoscopy, $14(14.7 \%)$ had antibodies to Chlamydia (Table 1).

Table 1: Tubal disease and chlamydial sero positivity.

\begin{tabular}{|c|c|c|c|c|c|c|c|c|c|}
\hline \multirow{3}{*}{ E/O tubal disease } & \multicolumn{4}{|c|}{ Chlamydia } & \multirow{2}{*}{\multicolumn{2}{|c|}{ Total }} & \multirow{3}{*}{$x^{2}$} & \multirow{3}{*}{ df } & \multirow{3}{*}{$\begin{array}{l}\text { p- } \\
\text { value }\end{array}$} \\
\hline & \multicolumn{2}{|c|}{ Positive } & \multicolumn{2}{|c|}{ Negative } & & & & & \\
\hline & $\mathbf{N}$ & $\%$ & $\mathbf{N}$ & $\%$ & $\mathbf{N}$ & $\%$ & & & \\
\hline Present & 14 & 14.7 & 81 & 85.3 & 95 & 100 & 0.512 & 1 & 0.474 \\
\hline Absent & 12 & 19 & 51 & 81 & 63 & 100 & & & \\
\hline Total & 26 & 16.5 & 132 & 83.5 & 158 & 100 & & & \\
\hline
\end{tabular}


Of the 63 patients with normal tubes, $12(19 \%)$ had Chlamydial positivity. The difference is not statistically significant. The sensitivity is $14.7 \%$ and specificity is $81 \%$.

Tubal disease was predominant in the age group 26-35 years (almost 75\%). Similarly Chlamydial antibodies were also more common after $26.73 \%$ of Chlamydia antibody positive patients were in the age group 26-35. Of the 95 patients with tubal disease, 61 patients $(64 \%)$ had primary infertility. Of those 26 patients who were Chlamydia positive, 22 patients $(84.6 \%)$ had primary infertility which is significant. Miscarriages were not commonly seen in patients with tubal disease or those with Chlamydia antibodies. Ectopic pregnancy had occurred in only $16.8 \%$ of the patients with tubal disease.
Similarly, only one patient of the 26 Chlamydia positive patients $(3.8 \%)$ had ectopic pregnancy. In the patients with tubal disease the significant signs and symptoms were chronic pelvic pain $(\mathrm{p}=0.018)$, tenderness in fornices during pelvic examination $(\mathrm{p}=0.009)$, presence of adnexal mass $(\mathrm{p}=0.027)$ and restricted mobility of the uterus $(\mathrm{p}<0.001)$.

Of the patients with tubal disease $46.3 \%$ had adnexal mass in ultrasonogram and of the Chlamydia positive patients $50 \%$ had adnexal mass. Of the patients with tubal disease $64 \%$ had block in one or both tubes, $70 \%$ had peritubal adhesions, $13.7 \%$ had hydrosalpinx and $62.1 \%$ had unhealthy looking tubes. The association of abnormal tubes (one or both) with Chlamydia is shown in Table 2. There is no statistical significance.

Table 2: Tubal disease seen at laparoscopy and chlamydial seropositivity.

\begin{tabular}{|c|c|c|c|c|c|c|c|c|c|}
\hline & \multicolumn{4}{|c|}{ Chlamydia } & \multirow{2}{*}{\multicolumn{2}{|c|}{$\begin{array}{l}\text { Total } \\
(\mathrm{N}=158)\end{array}$}} & \multirow[t]{3}{*}{$x^{2}$} & \multirow[t]{3}{*}{ df } & \multirow[t]{3}{*}{ p- value } \\
\hline & \multicolumn{2}{|c|}{ Positive ( $\mathrm{N}=26)$} & \multicolumn{2}{|c|}{ Absent (N=132) } & & & & & \\
\hline & $\mathbf{N}$ & $\%$ & $\mathbf{N}$ & $\%$ & $\mathbf{N}$ & $\%$ & & & \\
\hline Absent spill & 6 & 23.1 & 55 & 41.7 & 61 & 38.6 & 3.167 & 1 & 0.075 \\
\hline Peritubal adhesions & 12 & 46.2 & 58 & 43.9 & 70 & 44.3 & 0.043 & 1 & 0.835 \\
\hline Hydrosalpinx & 2 & 7.7 & 11 & 8.3 & 13 & 8.2 & 0.012 & 1 & 0.913 \\
\hline Un healthy appearance & 6 & 23.1 & 53 & 40.2 & 59 & 37.3 & 2.707 & 1 & 0.100 \\
\hline
\end{tabular}

Chi-square test was used to analyse the variables. A p value of 0.005 was taken as the level of significance.

Even though obvious endometriosis on ultrasound was taken as an exclusion criterion, of the 95 patients with tubal disease $48.4 \% \quad(n=46)$ had evidence of endometriosis at laparoscopy like endometriotic deposits, adhesions and partial obliteration of the pouch of Douglas. Among the 46 patients with evidence of endometriosis, $7(15 \%)$ had antibodies to Chlamydia (Table 3).

Table 3: Evidence of endometriosis and chlamydial sero positivity.

\begin{tabular}{|c|c|c|c|c|}
\hline \multirow[t]{3}{*}{ Chlamydia } & \multicolumn{4}{|c|}{$\begin{array}{l}\text { Tubal disease with evidence of } \\
\text { endometriosis }\end{array}$} \\
\hline & \multicolumn{2}{|c|}{ Present } & \multicolumn{2}{|c|}{ Absent } \\
\hline & $\mathbf{N}$ & $\%$ & $\mathbf{N}$ & $\%$ \\
\hline Positive & 7 & 15.2 & 7 & 14.3 \\
\hline Negative & 39 & 84.8 & 42 & 85.7 \\
\hline Total & 46 & 100.0 & 49 & 100.0 \\
\hline
\end{tabular}

\section{DISCUSSION}

The present study sought to determine the association between Chlamydia trachomatis IgG antibodies and tubal factor infertility among infertile women with primary or secondary infertility attending the Fertility Clinic of a tertiary care hospital in Kerala, India. In the present study, the prevalence of Chlamydia IgG antibodies among women with primary or secondary infertility was found to be $16.4 \%(26 / 158)$. This result is consistent with various studies across the world as well as studies in India. In a study conducted at the Reproductive and Gynaecology departments of Aurobindo Medical college Indore in 2015 by Swapnil Singh et al; 10 out of 200 patients tested positive for Chlamydia $(5 \%){ }^{6}$

In the present study $73 \%$ of patients who tested positive for Chlamydia belonged to the age group 26-35. $26.9 \%$ patients were above 35 years of age. Tubal disease was also predominant in the age group 26-35 years. Almost $73 \%$ of the patients with Chlamydia positivity had been married for a period of less than 10 yrs. Similarly, 78\% of patients with tubal disease were married for a period of less than 10 years.

In a study of the prevalence of Chlamydia infection in Samoan women by Walsh et al participants who had a previous pregnancy were less likely to be positive (OR $0.49 ; 95 \%$ CI $0.27-0.87) .^{7}$ Primiparous and multiparous women were less likely to be positive than nulliparous women (OR 0.54; 95\% CI 0.30-0.99 and OR 0.46; $95 \%$ CI $0.24-0.89$, respectively). ${ }^{7}$ These findings were consistent with our results as $84 \%$ of patients in our study with antibodies against Chlamydia were being treated for 
primary infertility. Similarly, 64\% patients with tubal disease had primary infertility.

In the present study, of the 95 patients with abnormal tubes in laparoscopy determined by presence of tubal block, peritubal adhesions, hydrosalpinx and unhealthy appearance, only $14.7 \% \quad(n=14)$ had antibodies to Chlamydia, showing a sensitivity of $14.7 \%$ and specificity of $81.0 \%$. Of the patients with tubal disease in our study, $64 \%$ had block in one or both tubes, $70 \%$ had peritubal adhesions, $13.7 \%$ had hydrosalpinx and $62.1 \%$ had unhealthy looking tubes. In two studies by Land et al and by the WHO task force, it was found that among women with tubal pathology at laparoscopy, 60-70\% were Chlamydia antibody positive..$^{8,9}$

In the present study, the sensitivity is $14.7 \%$ and specificity is $81 \%$. This is similar to another Indian study by Swapnil et al, where the sensitivity was $20 \%$ and the specificity was $100 \% .^{6}$

Of the 26 patients in the present study with Chlamydia positivity $53.8 \% \quad(n=14)$ had tubal disease. This was consistent with results from various other studies showing tubal pathology at laparoscopy in $30-65 \%$ of Chlamydia antibody positive women. In another study by Shrikhande et al in Nagpur it was found that Chlamydia was responsible for $33 \%$ of cases with pelvic inflammatory disease. ${ }^{10}$

In the present study, of the 63 patients with normal tubes 12 patients (19\%) had Chlamydia positivity. The difference was not significant. In the Swapnil Singh study, however, it was negative in all 150 patients with normal tubes, giving a specificity of $100 \%$. One hypothesis to explain subfertility in patients with normal tubes but positive Chlamydia antibodies is that intratubal microdamage may have resulted from a previous Chlamydia infection that cannot be detected with conventional patency tests such as hysterosalpingogram or laparoscopy. In addition, these tests have interobserver variability, but it is unlikely that this would explain the substantially lower pregnancy rates in Chlamydia positive women.

Another hypothesis is that persistent Chlamydia infections also elicits an autoimmune response to human heat shock proteins (HSPs) due to their structural similarity with Chlamydia HSP. Human HSPs play an important role in early pregnancy. Animal as well as human research indicate that autoimmunity to human HSP exerts a negative influence on embryo development and implantation. ${ }^{11-14}$

\section{Limitation of the study}

As the study was conducted at a tertiary centre where most of these patients were referred, it is likely that many had already received syndromic treatment for various complaints.

\section{CONCLUSION}

This study showed no difference in Chlamydial antibody positivity between women with tubal factor infertility and those without. Patients with normal tubes in laparoscopy had Chlamydial antibodies in similar proportion to those with abnormal tubes. The absence of Chlamydial antibodies cannot be taken as a marker for normal tubes. Hence screening for Chlamydial antibody can neither be used as a screening test for tubal factor infertility nor to decide the need for laparoscopy in our population.

Funding: SAT Endowment Fund

Conflict of interest: None declared

Ethical approval: The study was approved by the Institutional Ethics Committee

\section{REFERENCES}

1. Lalos O. Risk factors for tubal infertility among infertile and fertile women. Eur J Obstet Gynecol Reprod Biol. 1988;29:129.

2. Rosenfeld DL, Seidman SM, Bronson RA, Scholl GM. Unsuspected chronic pelvic inflammatory disease in the infertile female. Fertil Steril. 1983;39:44

3. Ljubin-Sternak S, Meštrović T. Chlamydia trachomatis and Genital Mycoplasmas: Pathogens with an Impact on Human Reproductive Health. J Pathog. 2014;2014:183167.

4. Sharma H, Tal R, Clark NA, Segars JH. Microbiota and Pelvic Inflammatory Disease. Semin Reprod Med. 2014;32(1):43-9.

5. Lis R, Rowhani-Rahbar A, Manhart LE. Mycoplasma genitalium infection and female reproductive tract disease: a meta-analysis. Clin Infect Dis. 2015;61(3):418-26.

6. Singh S, Bhandari S, Agarwal P, Chittawar P, Thakur R. Chlamydia antibody testing helps in identifying females with possible tubal factor infertility. Int $\mathrm{J}$ Reprod Biomed (Yazd). 2016;14(3):187-92.

7. Walsh MS, Hope E, Isaia L, Righarts A, Niupulusu T, Temese SV, et al. Prevalence of Chlamydia trachomatis infection in Samoan women aged 18 to 29 and assessment of possible risk factors: a community- community-based study. Trans R Soc Trop Med Hyg. 2015;109:245-51.

8. Land JA, Gijsen AP, Kessels AGH, Slobbe MEP, Bruggeman CA. Performance of five serological chlamydia antibody tests in subfertile women. Hum Reprod. 2003;18:2621-7.

9. WHO Task Force on the Prevention and Management of Infertility. Tubal infertility: serologic relationship to past chlamydial and gonococcal infection. Sex Transm Dis. 1995;22:71-7.

10. Shrikhande SN, Joshi SG, Zodpey SP, Saoji AM. Chlamydia trachomatis in pelvic inflammatory disease. Indian J Pathol Microbiol. 1995;38:181-4. 
11. Neuer A, Spandorfer SD, Giraldo P, Dieterle S, Rosenwaks Z, Witkin SS. The role of heat shock proteins in reproduction. Hum Reprod Update. 2000;6:149-59.

12. Witkin SS. Immunity to heat shock proteins and pregnancy outcome. Infect Dis Obstet Gynecol. 1999;7:35-38.

13. Witkin SS. Immunological aspects of genital clamydia infections. Best Pract Res Clin Obstet Gynaecol. 2002;16:865-74.
14. Witkin SS, Sultan KM, Neal GS, Jeremias J, Grifo JA, Rosenwaks Z. Unsuspected Chlamydia trachomatis infection and in vivo fertilization outcome. Am J Obstet Gynecol 1994;171:1208-14.

Cite this article as: Balakrishnan $\mathrm{S}$, Malathi $\mathrm{A}$, Raveendran G, Johnrose D, Radha S. Role of IgG Chlamydia antibody in tubal factor infertility. Int $\mathbf{J}$ Reprod Contracept Obstet Gynecol 2017;6:837-41. 